\title{
Las retransmisiones deportivas radiofónicas en España: un análisis textual
}

\author{
The sport broadcastings in Spain: a textual analysis
}

Ddo. Francisco Javier Herrero Gutiérrez Universidad de Salamanca (España) javiherrero82@usal.es

Recibido: 25 de Octubre 2012 Aceptado: 30 de noviembre 2012

\section{Resumen}

Este artículo refleja los resultados referentes al nivel textual de un proyecto desarrollado sobre las retransmisiones deportivas radiofónicas en España. A partir de una muestra compuesta por grabaciones de 75 fragmentos radiofónicos de pruebas deportivas, y las posteriores transcripciones de dichos fragmentos, se ha realizado un acercamiento a un nivel textual, analizando más de 3.000 oraciones y 20.000 palabras.

\section{Abstract}

This article reflects the results about the text of a project developed about the sport broadcastings in Spain. From a sample composed by 75 recordings of fragments taken from radio about sports, and the later transcriptions of these mentioned fragments, an approach to a textual level has been realized, analyzing more than 3.000 sentences and 20.000 words.

Palabras Clave: Radio, deporte, comunicación

Key Words: Radio, sport, communication

\section{Introducción}

Este artículo refleja parte de los resultados de una investigación realizada sobre las retransmisiones deportivas radiofónicas en España. En este original en concreto se 
presentan los resultados referentes al aparto de la lingüística. De alguna forma, se puede decir que este estudio supuso una continuación de una investigación publicada con una muestra de menor tamaño (Herrero, 2009) y que desde agosto de 2009 continúa desarrollándose a un nivel mucho más amplio".

La idea de la realización del presente proyecto, en su ámbito global, nació amparada porque actualmente la radio deportiva en España tiene una relevancia más que imponente. No hay más que fijarse en las diferentes parrillas de las distintas emisoras radiofónicas para darse cuenta de ello, al poder observarse un gran número de programas deportivos respaldados por los altos niveles de audiencia según los datos que periódicamente arroja la AIMC (Asociación para la Investigación de Medios de Comunicación) a través del EGM (Estudio General de Medios).

A partir de este campo de trabajo, el objetivo presentado en este texto es el de recoger un análisis textual de las locuciones que se hacen dentro de este género y considerando, como bien apunta el periodista Del Olmo que "el lingüista puede encontrar en la radio un observatorio perfecto para conocer qué dirección lleva nuestro idioma"2. La realización de esta propuesta es posible a partir de las transcripciones que se hacen de una selección de fragmentos radiofónicos sobre este temática, una muestra de 75 locuciones y sus posteriores transcripciones textuales.

Estos aspectos temáticos han ido adquiriendo una mayor fortaleza desde el punto de vista científico durante los últimos años a pesar de que hasta hace no mucho ha existido un dejamiento histórico debido a que la información deportiva como tal ha tenido un cariz poco relevante y siempre secundario en las diferentes facultades que forman a futuros periodistas; por ello hubo quien reclamó que se hiciera más hincapié sobre este aspecto: "La información deportiva, como información especializada, debe ser acogida en los planes de estudio con más atención de la que ha recibido hasta ahora. Una presencia que se justifica por su peso en la sociedad de la comunicación" (Boet, en Blanco, 2002: 16) debido a que es "hoy una de las especializaciones periodísticas con un mayor número de seguidores" (Paniagua, 2003: 9) y respaldada desde el punto de vista de la historia ya que la información deportiva es "también, una de las que cuenta con una mayor antigüedad como parcela potenciadora de la difusión en un medio" (Paniagua, 2003: 9).

1 En el contexto de un proyecto más amplio sobre niveles de locución, lingüísticos y contextuales, (subvencionado y cofinanciado por la Junta de Castilla y León y el Fondo Social Europeo).

${ }^{2}$ Idea aportada durante el II Congreso Internacional de la Lengua Española, celebrado en Valladolid, en octubre de 2001. 


\subsection{Marco teórico: La redacción en las retransmisiones deportivas radiofónicas}

La misión que ha de tener el periodista radiofónico es la de manejarse siempre en los límites de la corrección pues como indica el periodista Del Olmo ${ }^{3}$ refiriéndose a su gremio: "Nuestra responsabilidad es obvia: La radio es un formidable portavoz, un enorme amplificador que difunde a millones de oyentes aciertos y errores, y, desgraciadamente, son estos últimos los más difíciles de corregir". Para ser entendido por la inmensa mayoría, con el transcurso de los años la radio ha ido depurando su lenguaje y buscando una mayor sencillez expresiva aunque ello no debe ser óbice para que una primera condición que deba tener la redacción radiofónica sea la corrección (Faus, 1974: 204) entendiendo que "todos los elementos empleados en la redacción deben ser correctos desde el punto de vista de la sintaxis, el léxico y la semántica" (Rodero, 2005: 54). Un análisis textual de los fragmentos radiofónicos requiere de una serie de transcripciones de dichos fragmentos pero no se debe olvidar que "la narración radial no es un texto depurado, el locutor no lo puede corregir, modificar o manipular con posterioridad; ni puede realizar una relectura reflexiva" (Medina, 1995: 78). Por ello, se debe tener en cuenta esta esencial diferencia entre un texto realizado para ser leído y otro diferente, transcrito, que se creó para ser oído.

\subsubsection{Léxico}

El léxico de este género debe ser claro, rico y entendible. No obstante, muchas veces se acusa a los periodistas deportivos de "empobrecer el vocabulario, de usar irresponsablemente los distintos niveles de la lengua y de favorecer una información dirigida al goce en vez de al desarrollo de la inteligencia" (Castañón, 1993: 9). Pero la claridad léxica de una retransmisión no debe estar enfrentada con la corrección y la verborrea aceptable ya que el objetivo es que el locutor "aumente su léxico de forma que pueda generar imágenes auditivas en la mente del oyente que estén más o menos acordes con cuanto sucede en el terreno de juego" (Blanco, 2002: 136).

El uso cada vez más especializado de vocablos deportivos ha generado que los estudios sobre vocabulario deportivo hayan ido creciendo con el paso de los años, sobre todo desde que en 1972 en los Juegos Olímpicos de Múnich, la organización editara un diccionario de deportes olímpicos en cuatro idiomas: inglés, francés, alemán y español, en el que se explica la definición de palabras y frases en 21 disciplinas olímpicas junto con un capítulo para términos deportivos generales, un vocabulario general y un glosario de temática periodística (Alcoba, 2005: 119). El total de palabras y frases que aparecen en el diccionario es de 3.409, "cifra extraída de sólo 21 deportes y demostración de la riqueza de términos deportivos, lo que indica la dificultad de los periodistas deportivos para comprender el significado de tantas palabras y frases" (Alcoba, 2005: 119). Desde entonces se han ido creando otra serie de

${ }^{3}$ Idea aportada durante el II Congreso Internacional de la Lengua Española, celebrado en Valladolid, en octubre de 2001. 
diccionarios y libros con temática especializada en vocabulario deportivo (por especialidades, anglicismos, etc.) (Castañón, 2001).

Y, concretamente en España, se han publicado investigaciones relacionadas con el lenguaje deportivo, entre los que se pueden destacar trabajos realizados por Castañón, autor de obras como "Diccionario terminológico del deporte" o "Tendencias actuales del idioma del deporte" -aparte de su página personal (www.idiomaydeporte.com), una absoluta referencia para la investigación del lenguaje deportivo; Nomdedeu, autor de la tesis "Terminología del fútbol y diccionarios: elaboración de un diccionario de especialidad para el gran público"; o Agulló, con "Diccionario de términos deportivos". Y es evidente que existen argumentos para realizar estudios científicos sobre el lenguaje deportivo, ya sea porque muchas frases "han sido trasvasadas de los estadios a gran número de ámbitos sociales" (Aleixandre et. al., 2007: 117) lo que ha provocado, además, un enlace medios de comunicación - vocabulario sociedad:

"El hecho de que los deportes sean fenómenos de masas conlleva que los términos que se emplean aparezcan en los diversos medios de comunicación como nunca había sucedido con otro ámbito temático. Y cuando una terminología aparece tan abundantemente en los medios, se convierte en conocida y usada por los hablantes, se banaliza. En este sentido, los lexicógrafos deberían hacer más hincapié en la terminología empleada en los deportes, pues es muy usada por los hablantes a pesar de que no goza de prestigio en el mundo cultural y académico". (Nomdedeu, 2003: 92).

\subsubsection{Vocablos clave}

Se puede decir que existen unas palabras clave, a veces bien empleadas pero de las que se abusa en otras ocasiones. Entrando a citar vocablos clave, en las retransmisiones deportivas suele ser habitual nombrar a los deportistas con motes o sobrenombres. Otro recurso lingüístico útil es el de las onomatopeyas, que en algún momento pueden resultar "ilustrativas y graciosas" (Blanco, 2002: 147). También es habitual la utilización de extranjerismos aunque autores como Grijelmo recomiendan que no se abuse de esta terminología pues gran parte de la sociedad está invadida por estas palabras, idea rubricada por otro autor al referirse a una jerga deportiva que "nos invade sin cesar diariamente" (Alonso, 1996: 111). Tal empleo de estos vocablos dentro de la jerga deportiva viene justificado por la relación entre el vocabulario y su país de origen (Aleixandre et. al., 2007: 118), especialmente del inglés (Alcoba, 1993). En lo que se refiere a los neologismos, hay también quien se muestra más proclive por la defensa en la incorporación de nuevas palabras siempre y cuando enriquezcan. Grijelmo señala al respecto: “¿Hemos de prohibir el neologismo? Por supuesto que no. Pero tampoco podemos aceptar la innovación empobrecedora, manipuladora... o simplemente inglesa" (Grijelmo, 1998: 233). 
Habitual también en este tipo de retransmisiones son los términos metafóricos que "resultan herramientas valiosísimas para generar imágenes auditivas en el oyente" (Blanco, 2002: 148); y tampoco hay que olvidar la terminología bélica, permitida desde el momento en que existe una confrontación pero que, no obstante, se trata de un vocabulario del que tampoco se debería abusar (Alcoba, 1993). Por último, hay que tener presente los latiguillos molestos, que deberían evitarse.

\subsection{Gramática y sintaxis}

En lo que a la claridad sintáctica respecta, en su día, Lázaro apuntaba: "La transgresión idiomática, con chillido incluido, es de norma en las crónicas deportivas orales" (Lázaro, 1999: 595). A partir de esta idea se interpreta que el locutor deportivo estaría más preocupado por gritar para que se le oiga bien y despreocupado por cómo cuenta los hechos. De entre los manuales preocupados por la sintaxis de las retransmisiones deportivas en la radio, se debe reseñar la multitud de consejos que recoge Blanco (2002: 134-135) en una de sus obras. Así es que, dice este autor, se deben combinar las frases cortas con las largas para evitar la monotonía; respetar una estructura gramatical lógica; usar los nombres evitando el sujeto elíptico; evitar cláusulas entre el sujeto y el verbo; no ofrecer exceso de información; fragmentar el discurso; tener preferencia por las oraciones coordinadas en lugar de las subordinadas para no desorientar al oyente; utilizar las circunstanciales de tiempo, modo y de lugar para realizar narración de acciones y discursos explicativos; usar las frases comparativas para ilustrar; emplear las subordinadas condicionales para elaborar discursos especulativos, las casuales para los argumentativos, las finales para los explicativos y las concesivas para expresar impedimentos a las acciones. También, señala el propio Blanco (2002: 146), que deberían evitarse expresiones soeces, malsonantes, poco tolerantes, irrespetuosas, racistas, sexistas, que desprestigien al rival y evitar el empleo de tópicos. De todo lo mencionado, al lenguaje deportivo históricamente se le ha acusado del excesivo empleo de tópicos pero "nada destroza más el estilo que la frase hecha, el lugar común, la idea esperada y consabida" (Grijelmo, 2008: 354).

En este mismo apartado, conviene reseñar que se deberían usar mejor los sustantivos positivos en lugar de los negativos ya que, en lo que sería un apartado sintáctico-gramatical, queda defendida la idea de que para radio -y en general, para los medios audiovisuales-, entre el 'no' y el 'si', el periodista debe quedarse con la afirmación.

Por su parte, el adjetivo permitirá emitir juicios de valor y adecuar las descripciones aunque debe emplearse con cuidado pues hay autores que dejan entrever que no sería buena una predisposición por usar el adjetivo para evitar que la noticia que debe ser meramente informativa "adquiera un sesgo opinativo y subjetivo" (Tirado et. al. 2003: 145).

En lo que atañe al aspecto verbal, lo ideal sería emplear las formas simples en lugar de las compuestas y evitar los verbos-comodín tales como ser, estar, haber, tener, hacer, poner, 
producir o ver. La narración deportiva exige el tiempo presente, relegando el pretérito para rememorar determinadas acciones. Por su parte, "la forma en -ra del subjuntivo se usa como pasado del indicativo sin duda con intención estilística. Es un rasgo arcaico y literario que el español ya no escuchaba sino en canciones populares ('amores que yo te diera...') y que hoy asocia a crónicas deportivas" (Romero, 1993: 36). Por su parte, el condicional no es demasiado empleado mientras que el futuro es usado con frecuencia "en los discursos sobre los cambios estratégicos" (Blanco, 2002: 150) dentro de las crónicas deportivas.

En lo que al aspecto adverbial se refiere se deben evitar los adverbios con la terminación en -mente. Por último, en lo que a las preposiciones respecta, cualquier manual radiofónico hace especial hincapié en la incorrección del dequeísmo y el incorrecto uso de "ante" en vez de "contra", "ganar de" en vez de "ganar por", "tener aspiraciones de" en vez de "tener aspiraciones a", etc.

\subsection{Semántica}

El lenguaje deportivo, aunque sea simple, no siempre va a ser accesible -sí entendido pero no accesible- a todo el mundo sino que va a depender de un factor clave: el interés que cada receptor demuestre por la temática deportiva. El objetivo de un locutor debería ser el de emplear un lenguaje lo más abierto y global posible pues como dice el periodista Grijelmo: "El uso de la jerga de un determinado ámbito o profesión no favorece en nada la claridad. Por tanto, le conviene huir del lenguaje especializado y explicar con términos comunes -pero no vulgares- las palabras técnicas o de un grupo reducido" (Grijelmo, 2008: 448).

\subsection{Objetivo e hipótesis}

El objetivo del estudio es poder seguir contribuyendo al estudio del lenguaje deportivo desde un punto de vista científico.

Las hipótesis, referidas a las retransmisiones deportivas radiofónicas, sobre las que parte el presente trabajo son:

I Debería predominar el uso de oraciones simples frente a las compuestas.

II En lo que a la terminología respecta debería, predominar el empleo de nombres propios, sustantivos y verbos frente a adjetivos, adverbios y perífrasis verbales.

III Se prevén incorrecciones.

\section{Metodología}


En lo que a la metodología se refiere, este original se apoyará por una parte en la técnica cuantitativa "caracterizada como típica de las ciencias duras, ya que es rigurosa, sistemática y objetiva, se centra en el análisis de datos numéricos y utiliza para ello procedimientos estadísticos para el contraste de hipótesis" (Igartua, 2006: 92). Un análisis de contenido entendido como "un método de estudio y análisis de comunicación de forma sistemática, objetiva y cuantitativa, con la finalidad de medir determinadas variables" (Wimmer y Dominick, 1996: 170) - apoyado en el método científico, permitirá descubrir el "ADN de los mensajes" (Igartua, 2006: 181), pues hay que tener en cuenta que en el apartado de resultados se va a presentar un gran número de datos cuantificadores, que serán evaluados a través de cantidades porcentuales para alcanzar parte de las postreras conclusiones. Conjuntamente, dado el medio -la radio- y el material que se analiza -el lenguaje radiofónico, en su derivación textual, habrán de emplearse también técnicas cualitativas.

\subsection{Disciplinas convergentes al análisis lingüístico}

Dado que para realizar el análisis lingüístico se parte de unas transcripciones de fragmentos radiofónicos es importante señalar un conjunto de disciplinas que son de gran utilidad, tales como la Sintaxis, la Gramática generativa, la Gramática del texto o la Estilística. La Sintaxis debe ser entendida como "aquella rama de la Lingüística -ciencia referida exclusivamente a la lengua- que se ocupa de cómo han de construirse correctamente las oraciones de acuerdo con el código convencional vigente en un momento dado y en un grupo social concreto" (Martínez, 1992: 116). Así se podrá estudiar qué tipo de construcciones sintácticas se emplean y la corrección de éstas. En lo que atañe a la Gramática generativa, ésta es una ciencia "preocupada por la forma de los mensajes informativos" (Martínez, 1992: 116) y de ahí que una gramática generativa "tenga que ser un sistema de reglas capaz de reiteración para generar un número infinito de estructuras. Este sistema de reglas puede ser dividido en los tres componentes principales de una gramática generativa: los componentes sintáctico, fonológico y semántica" (Chomsky, 1971: 17). El problema central de esta Gramática es saber "cómo ha logrado el hablante construir esa oración [...] Si sustituimos el vocablo hablante por periodista, nos encontramos con el siguiente enunciado: cómo ha logrado el periodista construir esa oración" (Martínez, 1992: 119). El propio Martínez (1992), haciéndose partícipe de ideas de Lázaro, afirma que estas Gramáticas del texto se ocupan de elementos propiamente lingüísticos de los mensajes que constituyen las oraciones (fonológicos, morfológicos, sintácticos); la relación sintáctica de las oraciones entre sí para constituir los textos y también se ocupan de las condiciones que aseguran la coherencia semántica de los complejos oracionales. Por su parte la Estilística "aparece vinculada al habla individual de algunos usuarios privilegiados de la lengua: los grandes escritores" (Martínez, 1992: 116) si bien se puede entender esta definición como propia de la estilística literaria y no tanto de la oral, que es por la que principalmente se preocupa esta parte del estudio. 
Para realizar el análisis a partir de las transcripciones se debe tener en cuenta que aunque la mayoría de los estudios lingüísticos se centran especialmente en los textos escritos también se pueden trasladar las diferentes ideas al objeto aquí estudiado, el de las retransmisiones radiofónicas deportivas, pues cumplen el concepto de noticia marcado por Dijk:

"En otras palabras, en el uso diario, el concepto de la noticia en los medios
implica los siguientes conceptos: 1 . Nueva información sobre sucesos, objetos
o personas; 2 . Un programa tipo (de televisión o de radio) en el cual se
presentan ítems periodísticos; 3 . Un ítem o informe periodístico, como por
ejemplo un texto o discurso en la radio, en la televisión o en el diario, en el cual
se ofrece una nueva información sobre sucesos recientes" (van Dijk, 1990: 17).

Por ello que Dijk considere a la radio también como fuente de noticias a pesar de que no la tenga en cuenta para algunos de sus trabajos. También se tomarán nociones del análisis del discurso entendido como un concepto que denota "un enfoque teórico y metodológico del lenguaje y el uso del lenguaje. En este sentido, también se define por el objeto del análisis, específicamente los discursos, los textos, los mensajes, el habla, el diálogo o la conversación" (van Dijk, 1990: 44).

Dentro de todo el sistema textual conviene destacar que se tomará como base tanto a la palabra como a la frase u oración:

"Una palabra puede considerarse como unidad significativa aislada o como elemento de una unidad significativa más amplia, a la que suele llamarse oración. Si se considera como unidad la palabra, nos obligamos a considerar las restantes palabras como unidades de un conjunto que entre todas componen: el léxico de la lengua. Si la consideramos como elemento de la frase, nos obligamos a considerar las frases como unidades de significado y nos obligamos a estudiar la gramática de la lengua, las reglas que se aplican a la combinación de palabras para que constituyan frases" (Núñez, 1991: 171).

Presentado el planteamiento de las disciplinas expuestas, se podrá comenzar a realizar un primer acercamiento al análisis de las retransmisiones deportivas creando una primera tabla de ítems. Para crear esta tabla habrá que considerar la transcripción como una estructura lingüística susceptible de investigación. Este estructuralismo hay que tratarlo acompañado de la semiótica, entendiéndola como la ciencia que trata los sistemas de comunicación dentro de una sociedad. En lo que a los lenguajes audiovisuales se refiere, estas dos disciplinas han sido de vital importancia para las investigaciones y estudios (Rodríguez, 1998); también es aplicable, como consecuencia, para el lenguaje meramente auditivo, que es el que aquí se trata. En este sentido en el que se va a analizar este género radiofónico hay a uno o varios personajes principales por cada retransmisión que a fin de cuentas van a ser el autor o autores de los mensajes analizados. El fin último del texto, en este caso improvisado y a partir de las posibilidades lingüísticas, debe ser el de una correcta eficacia comunicativa 
(Rodríguez, 1998), teniendo en cuenta la influencia de diversos factores tales como la imparcialidad, exactitud, actualidad o inteligibilidad y considerando que estas cuatro categorías de la información periodística "actúan como axiomas en el proceso de delimitación de los conceptos de rigor periodístico y eficacia comunicativa, y éstos conforman una determinada medida de credibilidad" (Balsebre, 1994: 42). A partir de estas nociones, la tabla creada, y simplificada a los aspectos a estudiar en esta investigación, para el análisis quedaría encuadrada con los siguientes elementos (Tabla 1):

Tabla 1: Variables para analizar el nivel lingüístico

\begin{tabular}{|c|c|c|}
\hline \multicolumn{3}{|c|}{ NIVEL TEXTUAL } \\
\hline SINTAXIS & $\begin{array}{c}\text { Construcción de las } \\
\text { oraciones }\end{array}$ & Simples, compuestas \\
\hline LÉXICO & Terminología empleada & $\begin{array}{c}\text { Nombres propios, } \\
\text { sustantivos, verbos, } \\
\text { perífrasis verbales } \\
\text { adjetivos, adverbios, } \\
\text { otras partículas } \\
\text { (preposiciones, } \\
\text { conjunciones, artículos, } \\
\text { etc.) }\end{array}$ \\
\hline GRAMÁTICA & Construcción gramatical & Corrección, incorrección \\
\hline
\end{tabular}

Para analizar estos tres niveles, se recurrirá a la técnica del recuento para valorar diferentes aspectos.

\subsection{Objeto de estudio, material y sistema de trabajo}

Dentro de una investigación se debe entender que el objeto de estudio es la realidad sobre la que se va a trabajar. El presente texto tiene por objeto de estudio a las retransmisiones deportivas de la radio española que se emiten por sistema analógico en todo el territorio nacional a través de las cinco emisoras con más oyentes según el Estudio General de Medios, a fecha de obtención de la muestra (periodo 2008/09): cadena SER, cadena COPE, Radio Nacional de España, Onda Cero y Punto Radio. Los programas que formaron parte de esta investigación fueron los que se presentan en la siguiente tabla (Tabla 2): 
Tabla 2: Programas deportivos vigentes en el momento de obtención de la muestra

\begin{tabular}{|c|c|c|c|c|}
\hline Cadena SER & $\begin{array}{c}\text { Cadena } \\
\text { COPE }\end{array}$ & $\begin{array}{c}\text { Radio } \\
\text { Nacional de } \\
\text { España }\end{array}$ & Onda Cero & Punto Radio \\
\hline $\begin{array}{c}\text { Carrusel } \\
\text { Deportivo }\end{array}$ & $\begin{array}{c}\text { Tiempo de } \\
\text { Juego }\end{array}$ & $\begin{array}{c}\text { Tablero } \\
\text { Deportivo }\end{array}$ & Radioestadio & $\begin{array}{c}\text { El Mirador de } \\
\text { la Liga }\end{array}$ \\
\hline
\end{tabular}

En total: cinco programas referidos a otras tantas emisoras dentro de los que quedan encuadradas las retransmisiones deportivas que se realizan en la radio española.

Las transcripciones de los 75 fragmentos grabados han sido el material utilizado para realizar el estudio. Dichas transcripciones textuales han sido posibles gracias a la recogida de datos, que ha estado basada en la grabación de fragmentos radiofónicos sobre acontecimientos deportivos. La unidad de análisis serán las 75 transcripciones textuales de las mencionadas grabaciones.

Además, para la realización de este estudio se diseñó un libro de códigos y una ficha de análisis, herramientas que sirvieron a los codificadores para realizar el análisis pretendido. La codificación fue realizada por tres codificadores, tras el pertinente entrenamiento para evitar la influencia de los diferentes estilos personales.

\subsection{Universo y muestra}

El universo del objeto de estudio atañe a cualquier retransmisión deportiva radiofónica que se produzca en cualquiera de las cinco principales emisoras radiofónicas de España y que transmita por sistema analógico a todo el territorio español (cadena SER, cadena COPE, Radio Nacional de España, Onda Cero y Punto Radio).

Dado que es un universo extremadamente amplio y en constante crecimiento, la muestra empleada es la de conveniencia, justificada porque: "The material being studied must be difficult to obtain [...] Resources limit the ability to generate a random sample of the population [...] The third condition justifying convenience sampling is when a researcher is exploring some underresearched but important area" (Riffe, et. al., 1998: 85). Para realizar este muestreo de conveniencia, los criterios que se emplearon fueron:

a-) Retransmisiones referidas a los años 2008 y 2009

b-) Retransmisiones preferentemente emitidas por la SER, al tener en cuenta que era la emisora -y lo sigue siendo- de mayor audiencia según el EGM durante el periodo estudiado (Gráfico 1): 


\section{Gráfico 1: Emisoras analizadas}

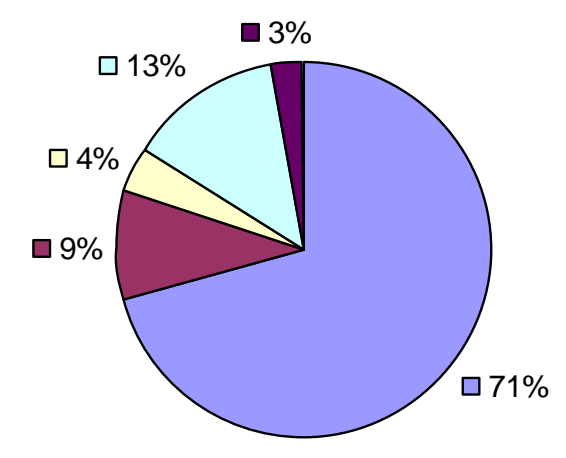

$\square$ Cadena SER

$\square$ Cadena COPE

$\square$ Radio Nacional de España

$\square$ Onda Cero

- Punto Radio

c-) Retransmisiones, especialmente, dedicadas al deporte del fútbol. Los otros deportes que forman parte de este estudio de carácter exploratorio son: el ciclismo, el tenis y el baloncesto (Gráfico 2):

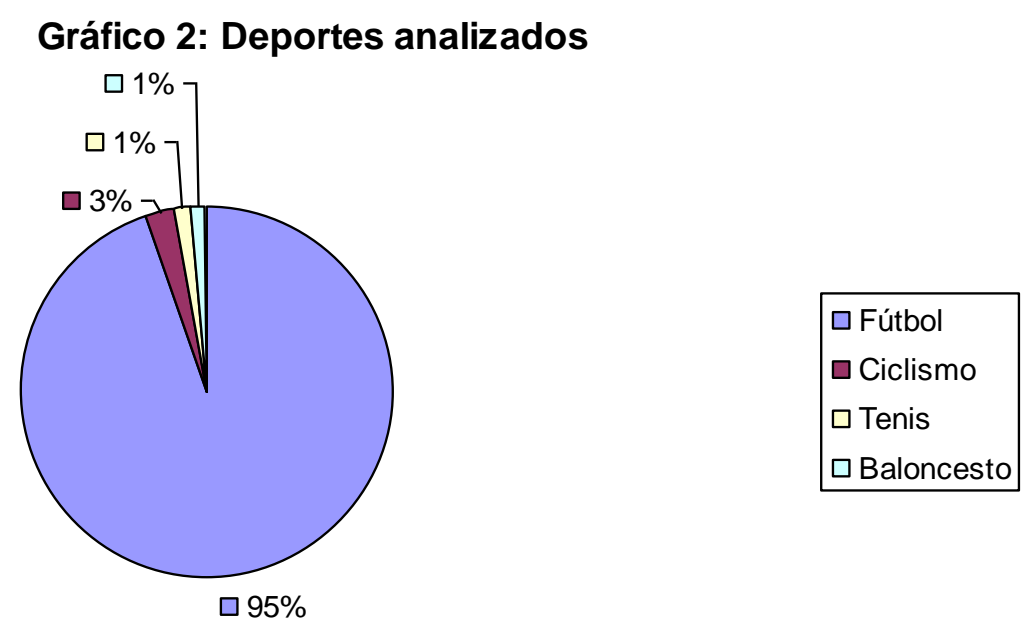

Facultad de Ciencias de la Información - Universidad de La Laguna

Avenida César Manrique, s/n; Campus de Guajara

38071 La Laguna, Tenerife (Islas Canarias - España) 


\section{Resultados}

\subsubsection{Resultados principales: análisis lingüístico}

Del análisis lingüístico, de entre las 3.325 oraciones analizadas, cabe destacar la predominancia de las oraciones simples (2.661 oraciones) sobre las compuestas (664). Porcentualmente, de entre los fragmentos analizados, la media es de un $80 \%$ de oraciones simples frente al $20 \%$ de oraciones compuestas (Gráfico 3):

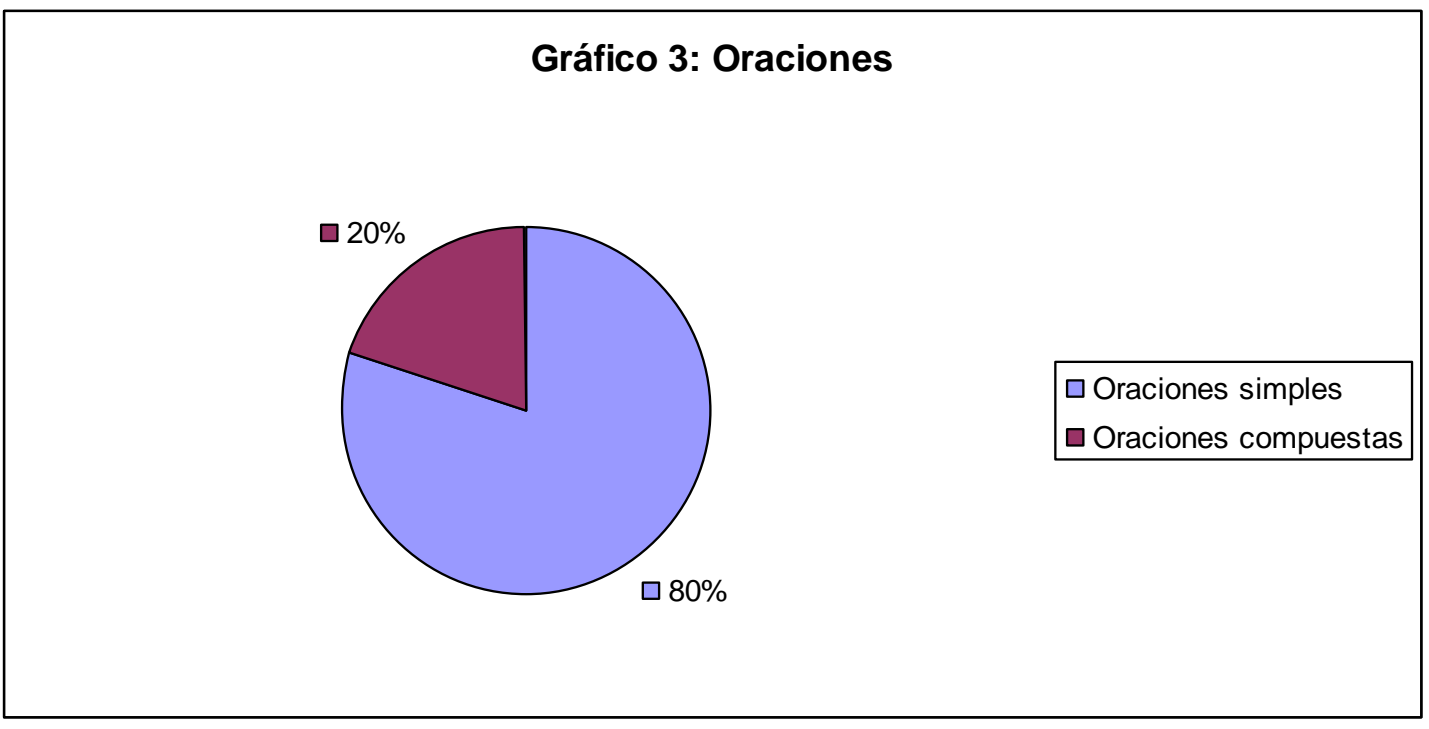

Para estimar un número de términos dentro de este tipo de género radiofónico, hay que recordar que se diseñó una tabla en la que se incluían nombres propios, sustantivos, verbos, perífrasis verbales, adjetivos, adverbios y resto de partículas empleadas. En este sentido, de entre los 20.295 términos analizados se obtuvieron unos resultados que arrojan los siguientes datos: 3.001 términos empleados son nombres propios (14,8\%); 3.203 son sustantivos (15,8\%); 2.598 son verbos (12,8\%); 502 son perífrasis verbales $(2,5 \%) ; 1.812$ son adjetivos $(8,9 \%) ; 1.233$ son adverbios $(6,1 \%)$ y 7.935 son otros términos lingüísticos $(39,1 \%)$ (Gráfico 4): 


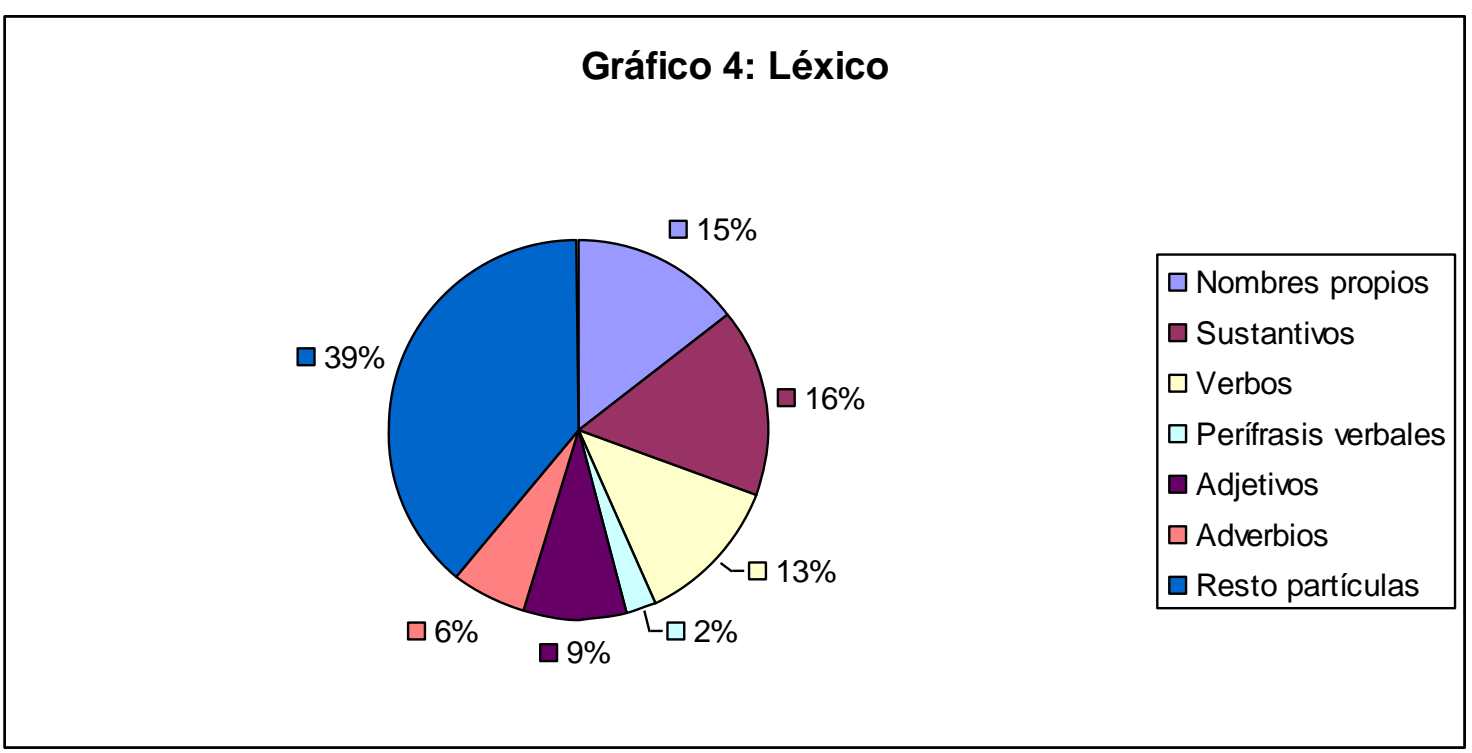

Por otra parte, de entre las flagrantes ${ }^{4}$ incorrecciones que se comenten se han encontrado un total de 56 y han quedado muy repartidas (Gráfico 5) entre incorrecciones gramaticales, con un total de $25(53,3 \%)$, y oraciones mal construidas: 31 (46,7\%).

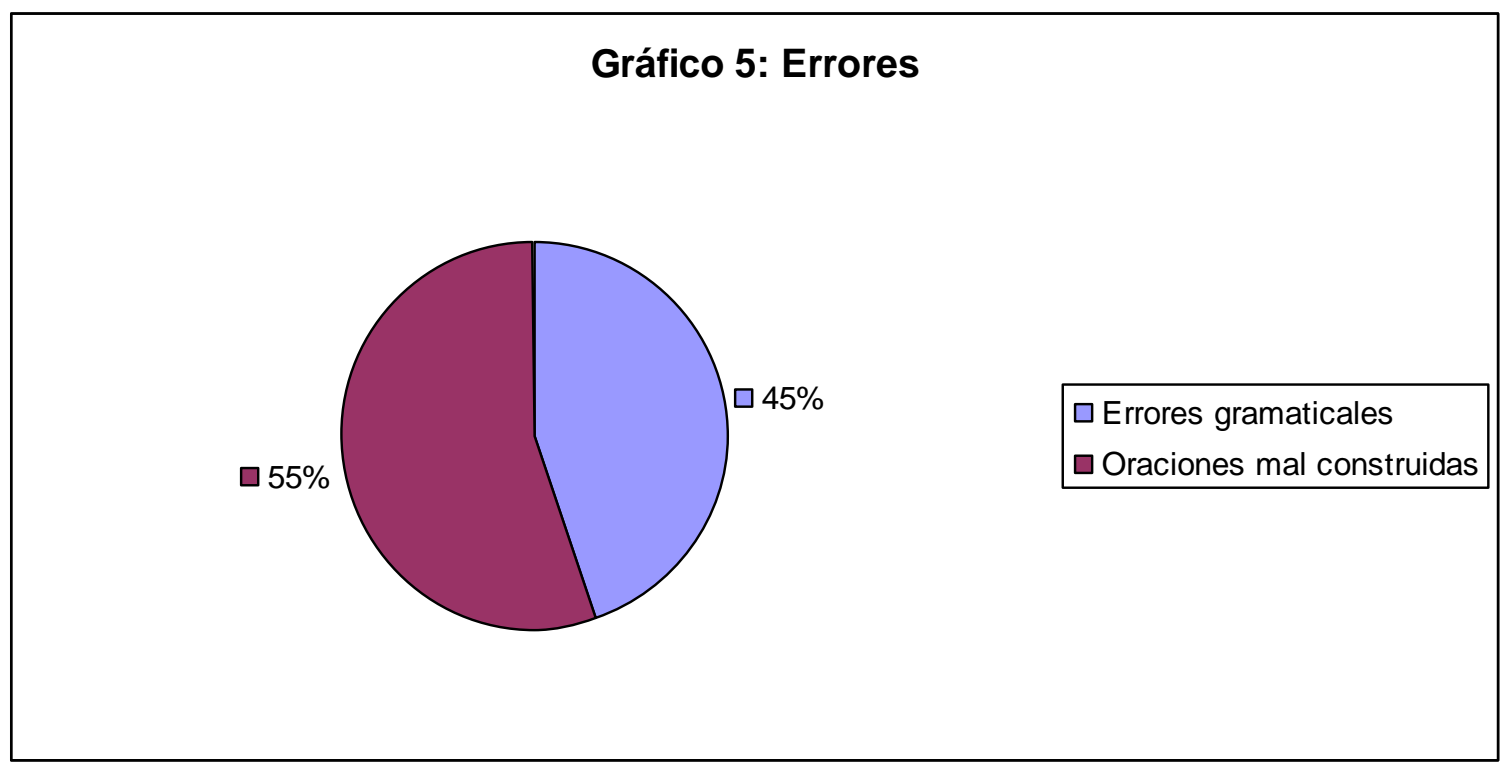

${ }^{4}$ No se han tenido en cuenta las palabras mal pronunciadas. Ej.: "Cuidao" para referirse a "cuidado". 


\subsubsection{Resultados secundarios}

Aunque no estaba previsto en el apartado de hipótesis, también conviene destacar que todos los fragmentos analizados (los 75: el 100\%) se producen en directo. Asimismo, son mínimas las veces en las que se escucha una voz del sexo femenino en la retransmisión; en cualquier caso, en este mismo sentido, cuando se analiza la voz del narrador principal de la locución del acontecimiento deportivo, en el $100 \%$ de los casos la voz corresponde a una voz del sexo masculino.

\subsection{Discusión de los resultados}

\subsubsection{Análisis lingüístico}

Del análisis lingüístico destaca el predomino de oraciones simples frente a oraciones compuestas $(80 \%$ frente a $20 \%)$. Se concluye así que los narradores deportivos de radio siguen las consignas para la redacción en radio y que marcan sus puntos fuertes en el no empleo de oraciones complejas y enrevesadas sino en oraciones simples y cortas con muchos puntos y seguido: una narración muy simple y lineal que impide que el receptor pueda desconcentrarse y perder el hilo de la narración. A pesar de ello, el abrumador empleo de frases cortas se contradice con una de las recomendaciones realizadas por algún autor que cree adecuada la combinación de frases cortas y largas para que el ritmo no sea monótono (Blanco, 2002: 134).

De entre los términos analizados, y vistos los datos expuestos en el apartado de resultados, se pueden destacar varios aspectos. Dejando a un lado un gran porcentaje de términos $(39,1 \%)$ referidos a artículos, preposiciones, conjunciones, etc., de entre los restantes destaca el porcentaje del 14,8\% referido a la mención de nombres propios -sólo superado por los sustantivos. Durante una retransmisión deportiva radiofónica se emplean un gran número de estos términos para nombrar a jugadores, árbitros, equipos de fútbol, Selecciones o para que los propios periodistas se nombren entre sí. Ello viene justificado por el hecho de que es preferible utilizar estos nombres propios para evitar el sujeto elíptico y para recordar el sujeto en las acciones (Blanco, 2002: 134-135). También destaca el poco uso que se hace de las perífrasis verbales -no así de verbos- atendiendo a razones de entendimiento y conocimientos del lenguaje radiofónico con el fin de que el narrador deportivo radiofónico no se inmiscuya en una verborrea ininteligible. Cabe destacar asimismo el bajo porcentaje de adjetivos utilizados lo que de alguna manera ampara la idea de que el lenguaje radiofónico deportivo carece de un exceso de floritura. Asimismo, es bajo el número de adverbios.

Por último, en lo que a los errores respecta, están equilibrados entre errores gramaticales y oraciones mal construidas. Se entiende aquí que existe un problema de cara a la sociedad 
pues la trascendencia que la radio tiene es tan profunda (Giddens, 2001) que gran parte de información, entre ella los errores, son los "que utilizamos en nuestra vida y la configuran" (Giddens, 2001: 504).

\subsubsection{Resto de los resultados}

Caben destacar dos: Las retransmisiones deportivas radiofónicas se producen siempre en directo. Salvo que a veces se dedican minutos para revivir momentos pasados, el "falso directo" es una modalidad que, a diferencia de la televisión, no tiene cabida en la radio deportiva. En segundo lugar hay que destacar la casi nula intervención de voces del sexo femenino en los fragmentos analizados. Además, cuando participan mujeres periodistas en este tipo de programas, dicha participación suele reducirse a papeles secundarios mientras que los acontecimientos deportivos de mayor relevancia son narrados por hombres. Paradójicamente también se puede reseñar que la mayoría de los deportes narrados tienen al hombre como protagonista de la prueba deportiva. Quizás, la justificación a tal circunstancia se encuentre en que el deporte se asemeja en gran medida a estereotipos masculinos (Santos et. al., 2005).

\section{Conclusiones}

Las hipótesis I y II quedan aceptadas al corroborarse el empleo mayoritario de oraciones simples y un vocabulario referente a los nombres propios, sustantivos y verbos, quedando en un segundo plano las perífrasis verbales, los adverbios y los adjetivos.

Los resultados hallados no permiten aceptar ni rechazar la hipótesis III ya que, si bien es cierto que se cometen incorrecciones, no se puede calibrar hasta qué punto son abundantes si se tiene en cuenta el medio de transmisión oral estudiado.

\subsection{Futuras investigaciones}

Este estudio, unido a otros anteriores sobre lingüística (Herrero, 2009) o los elementos de la locución (Herrero y Rodríguez, 2009) pretende seguir teniendo una mayor continuidad. Aparte de seguir estudiando la terminología existente presentada en este trabajo, pueden tener cabida otras muchas variables, como el empleo y la utilización de tópicos, neologismos, extranjerismos, préstamos, relación terminológica con otros campos semánticos, etc. Igualmente, tanto lo lingüístico como las variables de locución pueden ser mejor interpretadas si se tiene en cuenta toda la vertiente contextual que rodea a este fenómenos de las retransmisiones deportivas en la radio española. 


\section{Bibliografía}

Agulló Albuixech, R. (2003). Diccionario de términos deportivos. Madrid: Espasa.

Alcoba, A. (2005). Periodismo deportivo. Madrid: Síntesis.

Alcoba, A. (1993). Cómo hacer periodismo deportivo. Madrid: Paraninfo.

Aleixandre Benavent, R.; Agulló Albuixech, R.; Agulló Calatayud, V. y Valderrama Zurián, J. C. (2007): "Terminología y lenguaje deportivo del fútbol". Cultura, ciencia y deporte. Volumen 2, número 6, junio de 2007. Disponible en: http://www.ucam.edu/ccd/numeros/vol2/vol.-2-2013-no-6-junio-2007/aleixandre-benaventr.-agullo-r.-agullo-v.-y-valderrama-zurian-j.-c.-2007-.-terminologia-y-lenguaje-deportivo-delfutbol-cultura-ciencia-y-deporte-6-2-117-123

Alonso, J. (1996): Anglicismos deportivos: uso y abuso en la información española. Valladolid: Junta de Castilla y León, Valladolid.

Balsebre, A. (1994): La credibilidad de la radio informativa. Barcelona: Feed-Back Ediciones.

Blanco, J. M. (2002): Las retransmisiones deportivas: técnicas de narración radiofónica. Barcelona: CIMS.

Castañón, J. (2004): Diccionario terminológico del deporte. Asturias: Ediciones Trea.

Castañón, J. (2002): Tendencias actuales del idioma del deporte. Salamanca: Gráficas Lope.

Castañón, J. (2001): "El estudio científico del idioma del deporte en España". Idioma y deporte [en línea]. 15 de octubre de 2001, número 22. Disponible en: http://www.idiomaydeporte.com/lenciesp.htm ISSN: 1578-7281.

Castañón, J. (1993): El lenguaje periodístico del fútbol. Valladolid: Secretariado de Publicaciones Universidad de Valladolid.

Chomsky, N. (1971): Aspectos de la teoría de la sintaxis. Madrid: Aguilar.

Del Olmo, L.: "La radio, un idioma apasionado". Ponencia realizada durante el I/ Congreso Internacional de la Lengua Española, celebrado en Valladolid, en octubre de 2001. Disponible

en: http://congresosdelalengua.es/valladolid/ponencias/el espanol en la sociedad/2 la radio en espanol/olmo I.htm 
Faus, Á. (1974): La radio: introducción al estudio de un medio desconocido. Madrid: Guadiana de Publicaciones.

Giddens, A. (2001): Sociología. Madrid: Alianza Editorial.

Grijelmo, A. (2008): El estilo del periodista. Madrid: Taurus.

Grijelmo, A. (1998): Defensa apasionada del idioma español. Madrid: Taurus.

Herrero, F. J. (2009), “Una aproximación para una propuesta metodológica híbrida entre lo cuantitativo y lo cualitativo para el estudio de las retransmisiones deportivas en la radio española", Revista Internacional de Ciencias del Deporte, volumen V, año V, abril de 2009. Disponible en: http://www.cafyd.com/REVISTA/ojs/index.php/ricyde/article/view/231

Herrero Gutiérrez, F. J. y Rodríguez Ramos, D. (2009): "La locución de los narradores deportivos radiofónicos en España”, en Revista Latina de Comunicación Social, 64, páginas 968 a 987. La Laguna (Tenerife): Universidad de La Laguna, recuperado el 10 de diciembre de 2012, de:

http://www.revistalatinacs.org/09/art/874 Salamanca/75 101 Herrero.html

DOI: 10.4185/RLCS-64-2009-874-968-987

Igartua, J. J. (2006): Métodos cuantitativos de investigación en comunicación. Barcelona: Bosch.

Lázaro, F. (1999): El dardo en la palabra. Barcelona: Galaxia Gutenberg - Círculo de Lectores.

Martínez, J. L. (1992): Curso general de redacción periodística. Madrid: Paraninfo.

Medina, F. (1995): "Los narradores deportivos y sus epopeyas cotidianas", Estudios sobre las culturas contemporáneas, vol. 1, no 002, México, Universidad de Colima. Disponible en: http://redalyc.uaemex.mx/pdf/316/31600205.pdf

Nomdedeu, A. (2004): "Terminología del fútbol y diccionarios: elaboración de un diccionario de especialidad para el gran público". Tesis doctoral (dir. Cecilio Garriga Escribano). Departamento de Filología Hispánica. Universidad Autónoma de Barcelona. Consultada en: http://tdx.cat/handle/10803/4872

Nomdedeu, A. (2003): "La terminología del deporte en los diccionarios generales del español", Revista de Lexicografía, IX, La Coruña, 2003, pp. 57-95. Disponible en: http://ruc.udc.es/dspace/bitstream/2183/5474/1/RL_9-3.pdf 
Núñez, L. (1991): Manual para periodismo: veinte lecciones sobre el contexto, el lenguaje y el texto de la información. Barcelona: Ariel Comunicación.

Paniagua, P. (2003): Información deportiva: especialización, géneros y entorno social. Madrid: Fragua.

Riffe, D.; Lacy, S. y Fico, F. G. (1998): Analyzing media messages. Using quantitative content analysis in research. Mahwah (New Jersey): Lawrence Erlbaum.

Rodero, E. (2005): Producción radiofónica. Madrid: Cátedra.

Rodríguez, Á (1998): La dimensión sonora del lenguaje audiovisual. Barcelona: Paidós.

Romero, M. V. (1993): El español en los medios de comunicación. Madrid: Arco Libros

Santos, A.; Balibrea, E.; López, A. et. al. (2005): Mujer, deporte y exclusión: experiencias europeas de inserción por el deporte. Valencia: Universidad Politécnica de Valencia.

Tirado, J. A.; Ruiz, M. y Albar, M. I. (2003): Técnicas para leer y escribir en radio y televisión. Barcelona: Bosch.

Van Dijk, T. A. (1990): La noticia como discurso: comprensión, estructura y producción de la información. Barcelona [etc.]: Paidós Comunicación.

Wimmer, R. D. y Dominick, J. R. (1996): La investigación científica de los medios de comunicación. Barcelona: Bosch, Barcelona.

Páginas web:

www.aimc.es (Asociación para la Investigación de Medios de Comunicación)

www.idiomaydeporte.com (Página sobre Idioma y Deporte. ISSN 1578-7281)

\section{Forma de citar este artículo en bibliografías}

HERRERO GUTIÉRREZ, F. J. (2012): "Las retransmisiones deportivas radiofónicas en España: un análisis textual', en Revista PANGEA, 3, páginas 118 a 135 Red Académica Iberoamericana de Comunicación. Recuperado el de de 2 de: http://www.revistapangea.org 